\title{
PEMBERDAYAAN KADER POSYANDU DALAM PENCATATAN DAN PELAPORAN BERBASIS WEBSITE DI POSYANDU DESA TEGALTIRTO
}

\section{Empowerment of Posyandu Regency in Website-Based Listing and Reporting at Posyandu Village Tegaltirto}

\author{
Novi Indrayani ${ }^{1}$, Nonik Ayu Wantini ${ }^{1}$, Arum Kurnia Sulistyawati ${ }^{2}$ \\ ${ }^{1}$ Program Studi DIV Bidan Pendidik, Universitas Respati Yogyakarta \\ ${ }^{2}$ Program Studi S1 Sistem Informasi, Universitas Respati Yogyakarta \\ novi.indrayani@respati.ac.id
}

\begin{abstract}
ABSTRAK
Abstrak dalam bahasa Indonesia ditulis dengan singkat menggunakan Times New Roman font 10

Penggunaan internet dan teknologi Informasi di Posyandu Kanthil, Kamboja dan Soka di Desa Tegaltirto belum dimanfaatkan secara maksimal. Hal disebabkan karena pengetahuan dan sarana yang belum mencukupi. Kendala lain yang muncul terkait dengan sistem pencatatan, pelaporan dan pemantauan yang masih manual menjadi salah satu kendala yang dihadapi oleh kader dalam pelaksanaan kegiatan posyandu, karena data yang dapat dipantau hanya terbatas pada saat pelaksanaan posyandu dan data tersebut tidak lengkap. Pembuatan website Sistem Informasi Pelayanan Posyandu (SIPANDU) dilakukan dengan tujuan sebagai sarana untuk mempermudah pelaporan dan pemantauan bagi kader terkait pelayanan posyandu. Metode yang digunakan yaitu dengan memberikan edukai melalui pelatihan pengoperasian perangkat lunak dan perangkat keras. Evaluasi penggunaan perangkat lunak "Website SIPANDU" dilakukan setelah pelatihan selesai. Hasil yang didapatkan yaitu kader mampu mengoperasikan website SIPANDU dan 100\% memiliki sikap yang positive dalam menerima inovasi untuk sistem pencatatan dan pelaporan berbasis website.
\end{abstract}

Kata Kunci : Kader, Posyandu, Pencatatan, Pelaporan, SIPANDU

\section{ABSTRACT}

The use of the internet and information technology in Posanthandu Kanthil, Cambodia and Soka in Tegaltirto Village has not yet been utilized to the full. This is caused by insufficient knowledge and facilities. Other obstacles that arise related to the recording system, reporting and monitoring that are still manual is one of the obstacles faced by cadres in the implementation of posyandu activities, because the data that can be monitored is only limited to when the posyandu is implemented and the data is incomplete. The making of the Posyandu Service Information System website (SIPANDU) was carried out with the aim of being a means to facilitate reporting and monitoring for cadres related to posyandu services. The method used is to provide eduka through training in the operation of software and hardware. Evaluation of the use of "SIPANDU Website" software is carried out after the training is completed. The results obtained are cadres able to operate the SIPANDU website and $100 \%$ have a positive attitude in accepting innovations for website-based recording and reporting systems.

Keywords : Cadre, Posyandu, Recording, Reporting, SIPANDU

\section{PENDAHULUAN}

Posyandu (Pos Pelayanan Terpadu) merupakan salah satu bentuk Upaya Kesehatan Bersumberdaya Masyarakat (UKBM) yang dilaksanakan oleh, dari dan bersama masyarakat, untuk memberdayakan dan memberikan kemudahan kepada masyarakat guna memperoleh pelayanan kesehatan bagi ibu, bayi dan anak balita (KemenKes RI, 2012).

Pentingnya peranan kader dalam memberdayakan masyarakat guna menurunkan tingkat kematian bayi dan balita di Indonesia tidak diragukan lagi. Peningkatan motivasi dan komitmen kader perlu diberikan tidak saja dalam bentuk insentif materil namun juga dalam bentuk apresiasi dan dukungan moral. 
Kader harus memiliki persyaratan dasar baik pengetahuan dan keterampilan agar mereka dapat efektif dalam menjalankan peranannya (Iswarawanti, 2010, hal 173).

Menurut penelitian yang dilakukan oleh Dikson dkk, keberhasilan akan pelaksanaan pembangunan kesehatan masyarakat di Desa mnelalete tidak bias lepas dari berbagai dukungan dan peran aktif yang dilakukan oleh seluruh masyarakat. Dalam hal ini peran yang besar adalah peran kader Pos Pelayanan Terpadu (Posyandu) yang secara langsung berhadapan dengan berbagai permasalahan kemasyarakatan termasuk masalah kesehatan yang dihadapi oleh masyaraka (Dikson dkk, 2017, Hal 60-61).

Beberapa kendala di lapangan yang sering terjadi dalam layanan adminsitrasi Posyandu adalah SDM atau kader yang kurang berkompeten serta sistem dokumentasi data dan informasi kurang memadai (Dewi, S., 2017: 272-282).

Posyandu Kanthil, Kamboja dan Soka merupakan posyandu yang berada di Desa Tegaltirto, Kecamatan Berbah, Kabupaten Sleman, Daerah Istimewa Yogyakarta. Berdasarkan hasil studi pendahuluan di ketiga Posyandu tersebut, didapatkan total 5 kader penggerak dan 50 bayi dan balita di Posyandu Soka, 6 kader penggerak dan 40 bayi dan balita di Posyandu Kanthil sedangkan di Posyandu Kamboja terdapat 8 kader dan 55 bayi balita . Kegiatan di ketiga posyandu tersebut dilakukan setiap 1 bulan sekali. Adapun kegiatan yang dilakukan meliputi penimbangan berat badan, pemberian vitamin A dan pemberian makanan tambahan.

Pelaporan pelayanan di Posyandu
Kanthil, Kamboja dan Soka masih
menggunakan pencatatan manual. Alur
pelaporan dimulai dari kader yang melakukan
pencatatan pada saat pelaksanaan kegiatan
Posyandu. Di akhir kegiatan, laporan tersebut
direkapitulasi oleh Ketua Kader Posyandu.
Selanjutnya hasil pelaporan akan diserahkan ke
Puskemas Berbah untuk ditindaklanjuti sesuai
dengan permasalahan yang dilaporkan.

Gambar 1.1. Dokumentasi Kegiatan Manual di Posyandu Kanthil
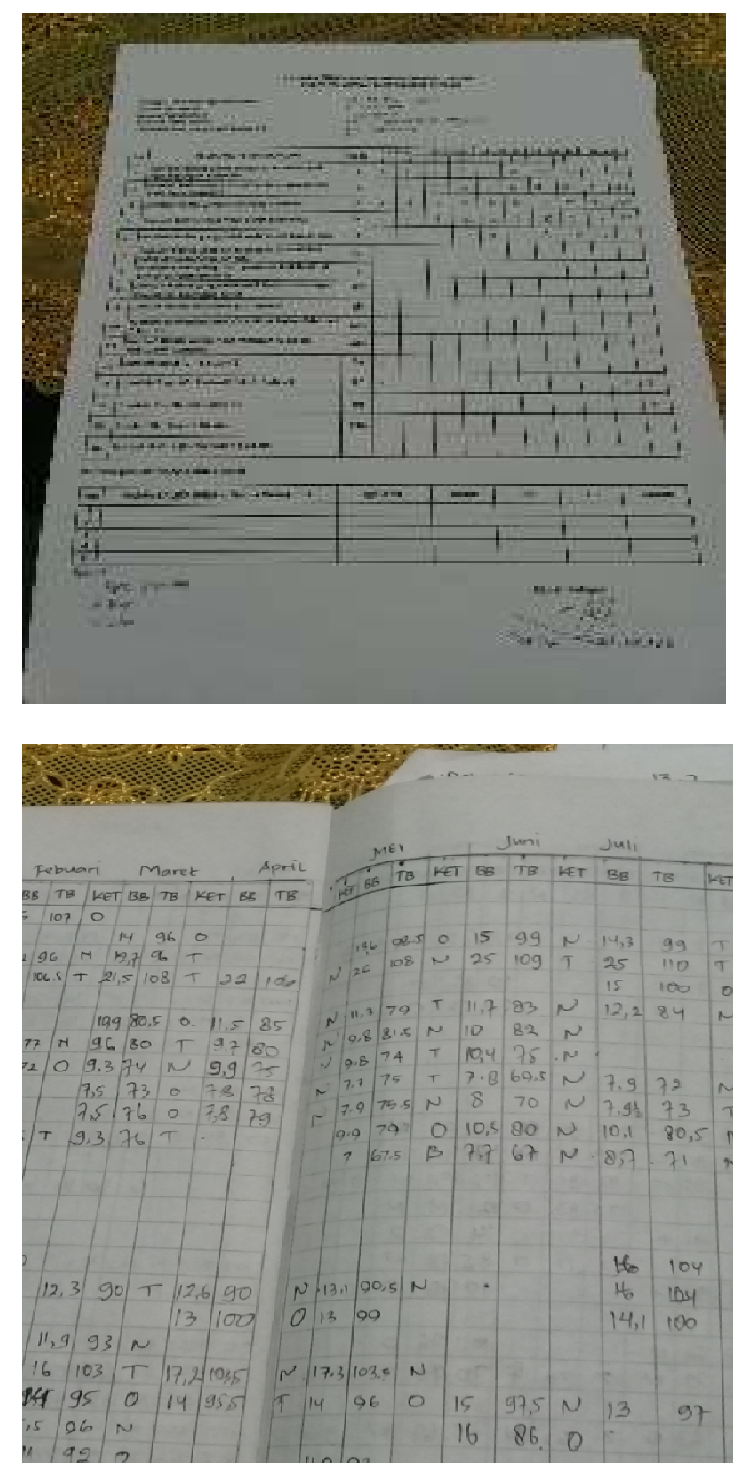

Gambar 1.2. Dokumentasi Kegiatan Manual di Posyandu Kamboja 

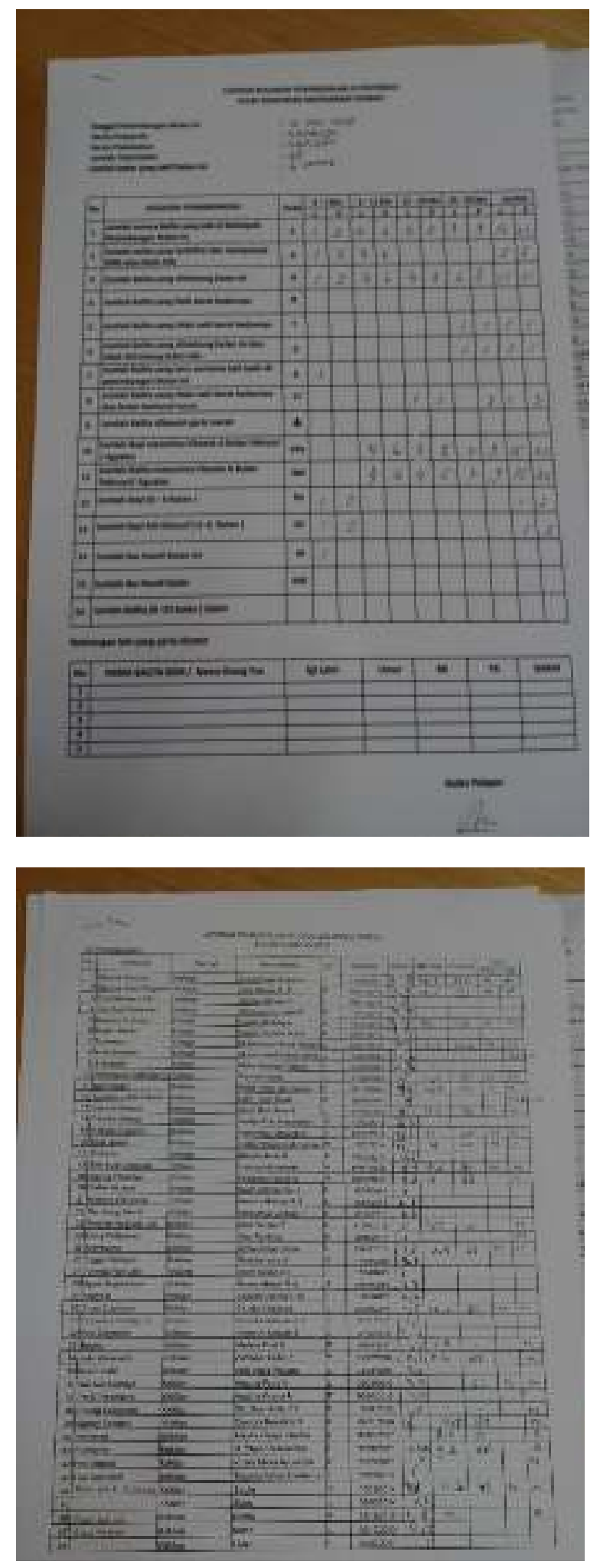

Gambar 1.3. Dokumentasi Kegiatan Manual di Posyandu Soka
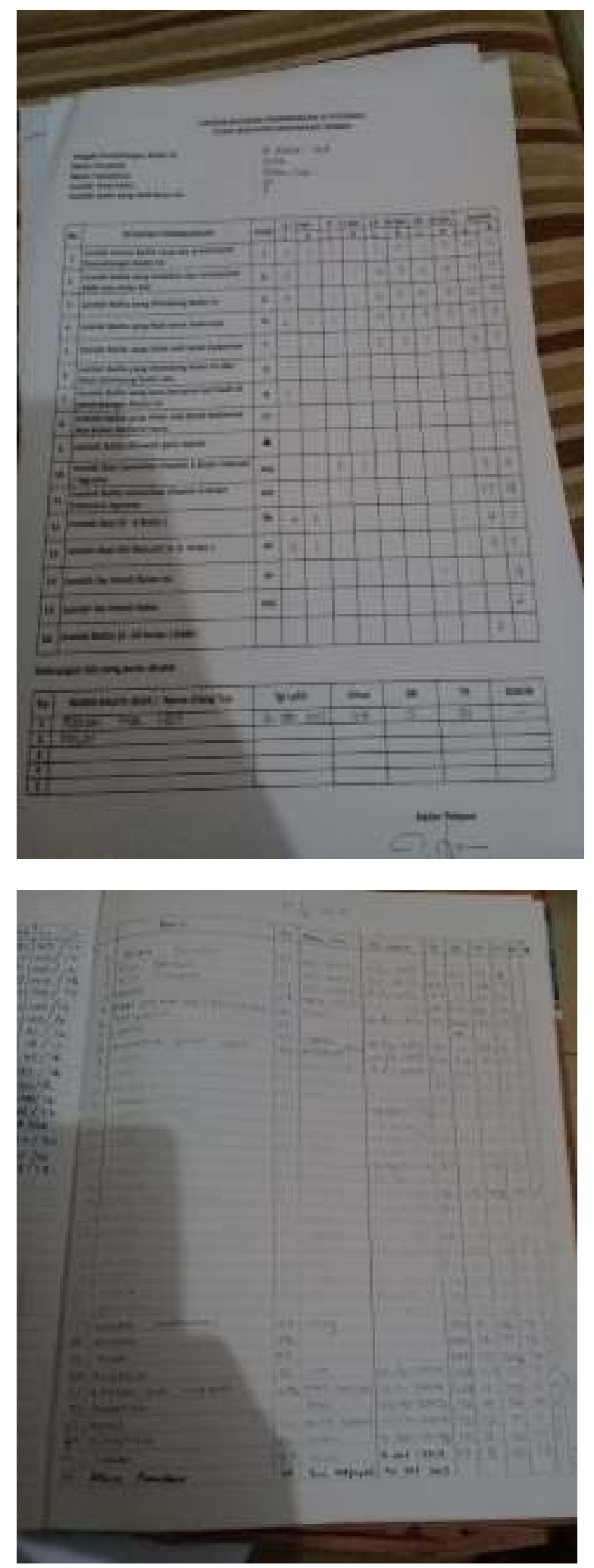
Mengingat perkembangan teknologi yang semakin pesat, pemanfaatan internet untuk mengakses informasi, pengiriman dan pelaporan dapat dimanfaatkan untuk mempermudah kegiatan posyandu. Akses internet sendiri sudah menjangkau wilayah Tegaltirto. Selain itu kader di Posyandu Kanthil, Kamboja dan Soka sudah terbiasa menggunakan gawai dan internet sebagai alat komunikasi. Ketua Kader Posyandu Kamboja sendiri pernah mendapatkan pelatihan penggunaan komputer pada tahun 2016 dan Ketua kader lainnya pun mampu mengoperasikan komputer. Ketua kader juga mengungkapkan mereka membutuhkan sarana atau aplikasi yang dapat digunakan untuk mempermudah pelayanan dan pelaporan di Posyandu. Pembuatan website Sistem Informasi Posyandu (SIPANDU) dilakukan dengan tujuan sebagai sarana untuk mempermudah pelaporan dan pemantauan bagi kader terkait pelayanan posyandu.

\section{METODE}

Pengabdian masyarakat ini dilaksanakan dari bulan Juli sampai dengan September 2019 di Posyandu Desa Tegaltirto, Kecamatan Berbah, Kabupaten Sleman, Provinsi DIY. Sasaran pada pengabdian ini yaitu perwakilan minimal 5 kader posyandu Kanthil, Kamboja dan Soka. Jumlah kader yang hadir yaitu 19 orang dengan sebaran 6 orang dari posyandu kanthil, 8 orang dari posyandu Kamboja dan 5 orang dari posyandu Soka. Adapun penentuan minimal kader yaitu mengacu pada pelayanan posyandu yang terdiri dari 5 meja sehingga pengabdi mewajibkan untuk minimal perwakilan kader yang hadir yaitu 5 orang.

Metode yang diberikan yaitu pemberian edukasi selama empat kali dan diakhiri dengan 1 kali simulasi. Lama pelatihan dalam satu kali pertemuan yaitu kurang lebih 5 jam. Edukasi yang diberikan yaitu melalui pelatihan dalam mengoperasikan perangkat keras, pengenalan aplikasi website "SIPANDU", cara mengoperasikan SIPANDU dan input data hasil dari posyandu.

Penyebaran kuesioner diberikan pada saat selesai seluruh pelatihan sebagai evaluasi kader dalam penerimaan terhadap sistem baru dan minat keberlangsungan penggunaan SIPANDU

\section{HASIL DAN PEMBAHASAN}

SIPANDU adalah singkatan dari Sistem Informasi Posyandu yang merupakan aplikasi berbasis teknologi informasi dan diperuntukkan bagi layanan informasi kegiatan di Posyandu Soka, Kamboja, dan Kantil yang berada di Kecamatan Berbah, Kabupaten Sleman, Yogyakarta. Pemilihan ketiga posyandu tersebut yaitu melalui rekomendasi dari pihak kelurahan untuk mewakili setiap bagian dari desa Tegal Tirto.

Adapun tujuan dari aplikasi SIPANDU ini adalah untuk melakukan pendataan secara online terhadap seluruh pasien, khususnya bayi dan balita, menyimpan data-data hasil pemeriksaan, serta menyajikan laporan hasil pemeriksaan pasien kepada ibu /balita dan kepada pihak Puskesmas Tegaltirto, Kecamatan Berbah, Kabupaten Sleman, Yogyakarta. Agar dapat menyesuaikan dengan tingkat kebutuhan masing-masing pengguna serta dapat diakses di mana saja dan kapan saja, aplikasi SIPANDU ini dibuat dalam versi website. Aplikasi SIPANDU ini dapat diakses pada laman http://sipandu.info/.

\section{Website SIPANDU}

Aplikasi website SIPANDU dapat diakses oleh beberapa pihak antara lain admin web, kader posyandu, dan pihak Puskesmas Tegaltirto, Kecamatan Berbah, Kabupaten Sleman, Yogyakarta. Aplikasi ini terdiri atas beberapa menu untuk memasukkan data, mengubah, dan melihat laporan hasil pemeriksaan bayi dan balita. Namun masingmasing menu telah disesuaikan dengan kebutuhan setiap pengguna yang memiliki hak akses. Berikut adalah tampilan halaman beranda ketika mengakses laman website SIPANDU. 


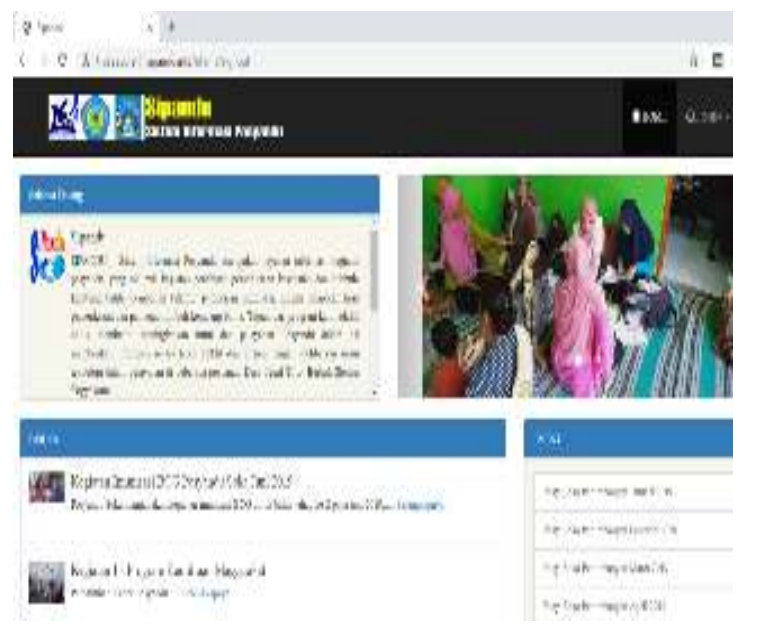

Gambar 1.1 Beranda Website SIPANDU

Pengguna harus memilih hak akses yang tepat sesuai dengan tugasnya. Ada tiga (3) jenis hak akses yang muncul ketika menu Login diklik, antara lain Admin, Puskesmas, dan Bidan/Kader. Pada saat pengguna sudah memiliki hak akses maka menu login sebagai berikut:

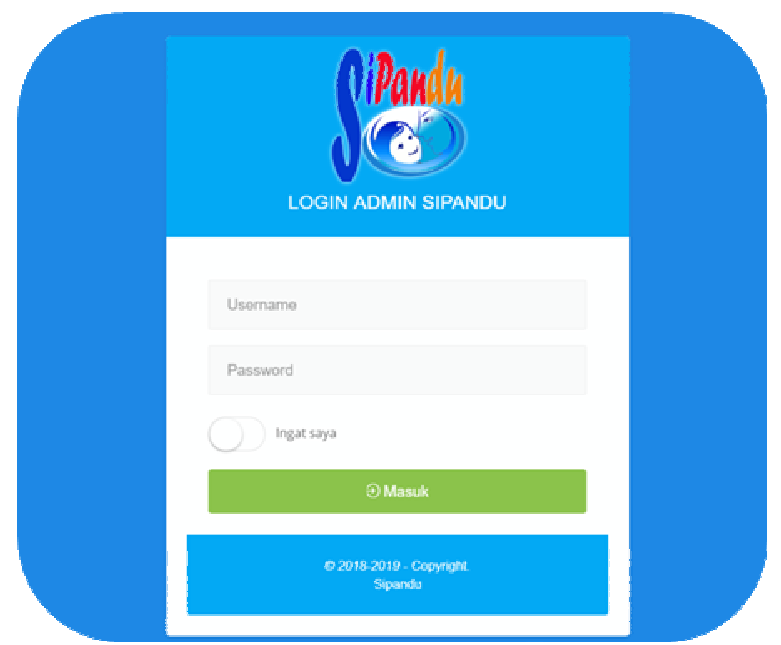

Gambar 1.2. Menu login pada SIPANDU

Hak akses pertama pada aplikasi SIPANDU adalah admin. Admin memiliki tugas dan tanggung jawab untuk memasukkan data posyandu yang dapat menggunakan aplikasi ini, mengatur akun pengguna, mengelola database masing-masing posyandu yang terlibat, serta memperbaharui berita, dan mengisi kegiatan penimbangan sesuai periode bulan penimbangan.
Menu yang dapat diakses oleh admin yang pertama yaitu menu posyandu. Menu ini merupakan menu untuk memasukkan, mengubah, ataupun menghapus data-data Posyandu yang dapat menggunakan aplikasi SIPANDU ini. Saat ini, hanya ada tiga Posyandu yang dapat menggunakan aplikasi ini yaitu Posyandu Soka, Kamboja, dan Kanthil seperti yang terlihat pada Gambar:

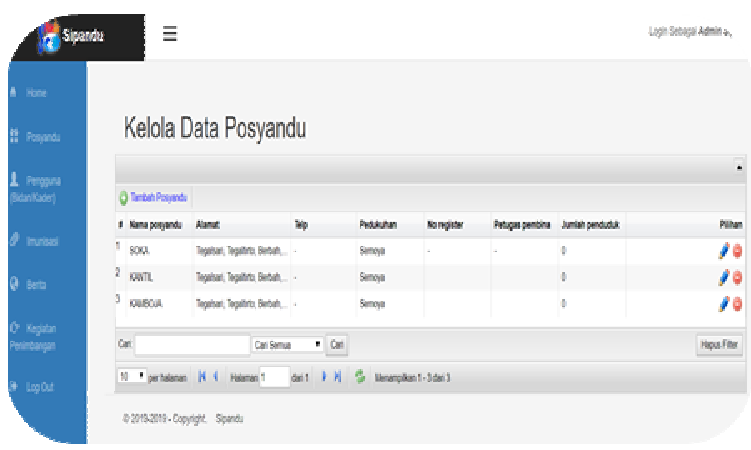

Gambar 1.3 Daftar iIdentitas Posyandu

Berikutnya yaitu menu pengguna dalam hal ini yaitu kader. Menu ini digunakan untuk mengelola data Kader Posyandu yang dapat menggunakan aplikasi SIPANDU. Masing-masing admin posyandu akan memberikan username dan password kepada kadernya masing-masing sesuai dengan input yang telah ditambahkan pada menu ini, tampilan menu sebagai berikut:

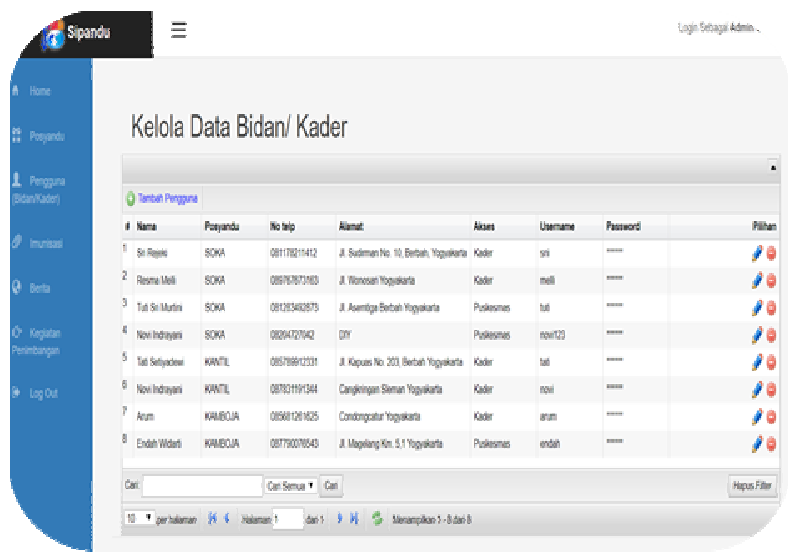

Gambar 1.4 Gambar Kelola Data Kader 
Menu berikutnya yaitu menu imuninsasi digunakan untuk menampilkan informasi perihal imunisasi yang dapat diberikan kepada balita seperti gambar berikut:

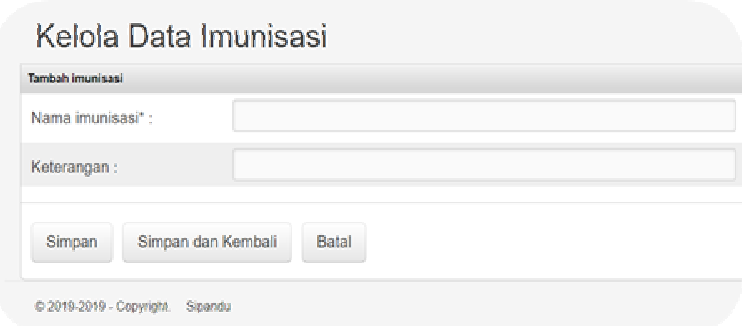

Gambar 1.5 Menu imunisas

Selain menu imunisasi ada menu berita. Menu berita digunakan untuk menampilkan berita perihal kegiatan posyandu, baik berupa kegiatan pemeriksaan, penyuluhan, pelatihan, dan lain-lain. Tampilan menu balita yaitu sebagai berikut:

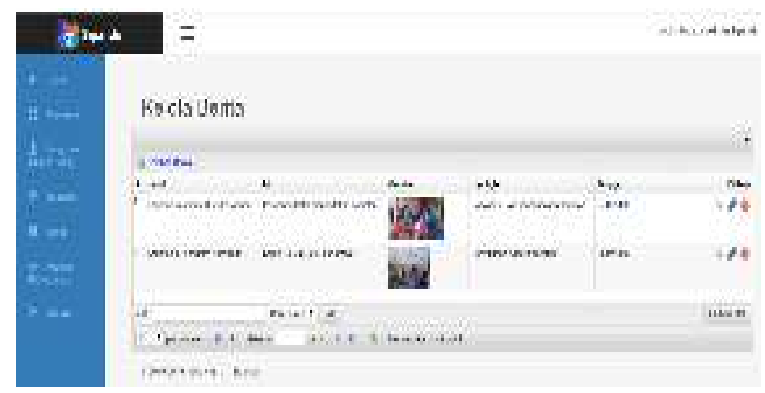

Gambar 1.6 Menu berita

Terakhir untuk menu yang dapat diakses oleh admin yaitu menu kegiatan posyandu. Menu Kegiatan Posyandu digunakan untuk menampilkan informasi kegiatan penimbangan di posyandu setiap bulan yaitu sebagai berikut:

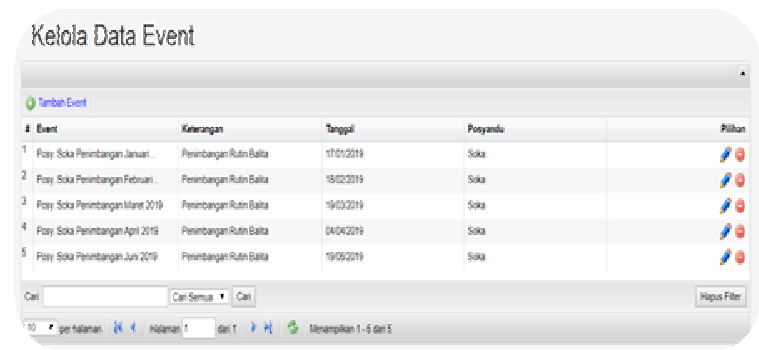

Gambar 1.7 Menu kegiatan posyandu
Hak akses kedua yang dapat mengakses aplikasi SIPANDU adalah kader. Kader memiliki tugas dan tanggung jawab dalam mengisi data hasil pemeriksaan balita di posyandu dan mengisi kegiatan penimbangan sebagai laporan bagi pihak puskesmas.

Menu yang dapat diakses oleh kader diantaranya yaitu menu balita. Menu Balita digunakan untuk memasukkan data hasil pemeriksaan balita di Posyandu. Menu ini mengijinkan para kader posyandu untuk menambah, mengubah, maupun menghapus data balita di posyandu. Berikut tampilan dari menu balita:

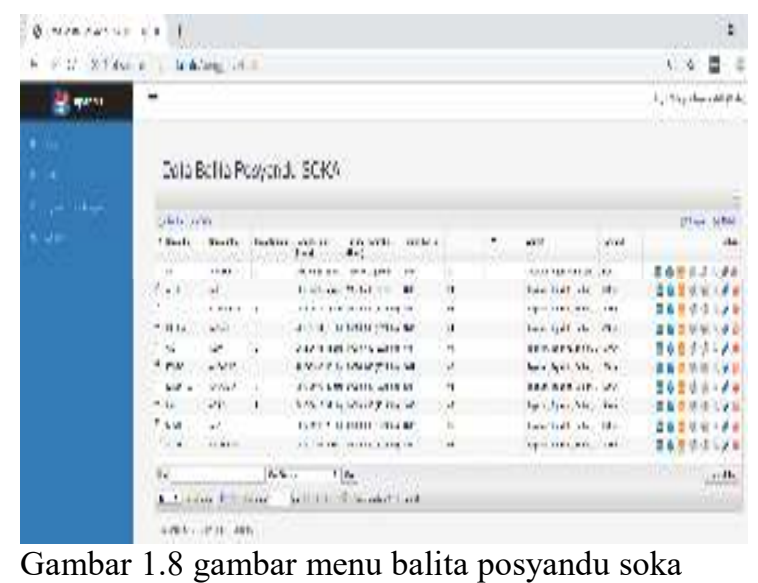

Keterangan gambar:

Ikon nomor 1: menambahkan Login Ibu untuk Ponsel Android.

Ikon nomor 2: input Pemberian Imunisasi.

Ikon nomor 3: input Pemberian Vitamin.

Ikon nomor 4: input Pemeriksaan Fisik.

Ikon nomor 5: view Hasil Pemeriksaan Fisik.

Ikon nomor 6: melihat Data Balita

Ikon nomor 7: mengubah Data Balita

Ikon nomor 8: menghapus Data Balita 
Menu kegiatan penimbangan digunakan untuk menampilkan informasi kegiatan penimbangan di posyandu setiap bulan. Tampilan menunya sebagai berikut:

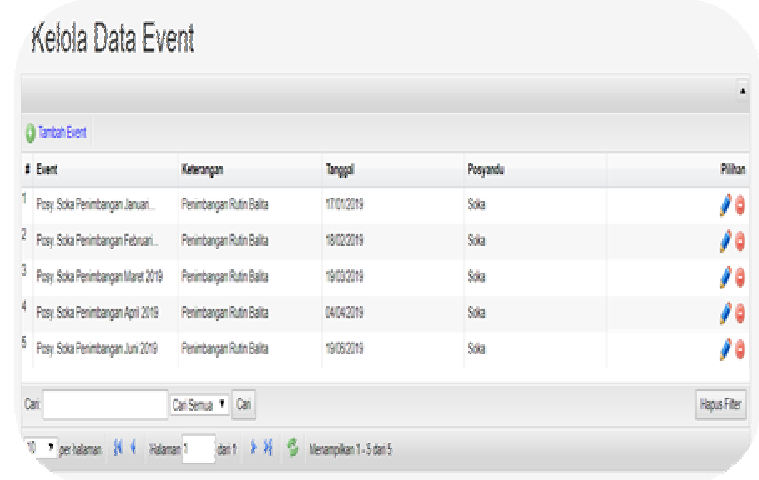

Gambar 1.9 Gambar kelola kegiatan penimbangan

Puskesmas dalam sistem ini bertindak sebagai level top-management sehingga hanya menerima dan melihat Laporan-laporan hasil pemeriksaan balita maupun event-event kesehatan yang telah di-input oleh para kader melalui aplikasi SIPANDU. Tiga jenis laporan yang dapat dilihat oleh pihak Puskesmas yaitu Tumbuh Kembang, Imunisasi, dan Daftar Balita, seperti Gambar berikut:

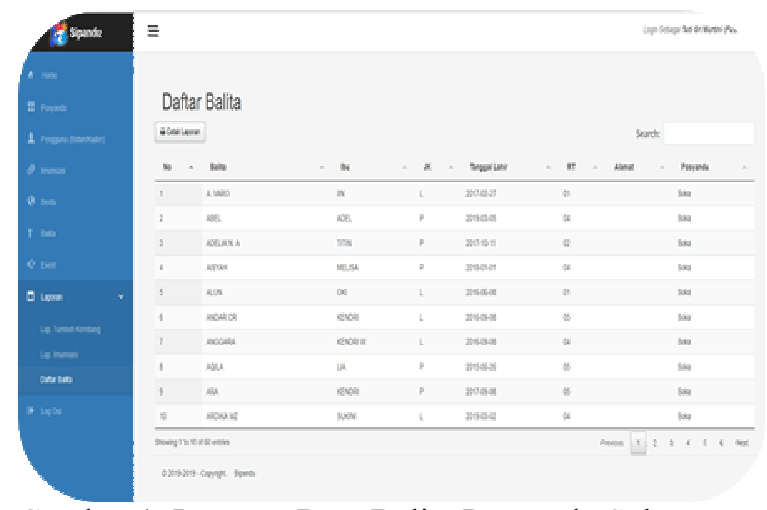

Gambar 1. Laporan Data Balita Posyandu Soka

\section{Aplikasi Android}

Selain dapat diakses melalui website untuk SIPANDU ini juga dapat diakses oleh ibu balita dalam bentuk aplikasi yang dapat diinstal di HP berbasis android. Ibu balita hanya dapat mengakses hasil pemeriksaan balitanya saja. Tidak dapat melihat data balita yang lainnya. Aplikasi SIPANDU untuk ibu balita sudah disinkronkan dengan data yang sudah diinput pada website SIPANDU oleh kader. Untuk aksesnya sendiri dapat melalui kader dengan cara kader mendaftarkan username dan password setiap ibu balita di menu akses kader. Fungsinya sendiri yaitu hampir sama dengan KMS (Kartu Menuju Sehat) milik balita yang harus dibawa setiap kali kunjungan.

Hal ini bertujuan yaitu untuk mempermudah ibu dalam memantau balitanya melalui ponsel genggam dan mengantisipasi apabila KMS hilang atau ibu lupa membawa KMS pada saat kunjungan ke Posyandu. Ibu dapat melihat data hasil pemeriksaan balitanya di Posyandu tidak hanya pada bulan tersebut namun pada beberapa bulan sebelumnya. Sehingga bu dapat membandingkan hasil pemeriksaan bulan ini dan sebelumnya.

Sebelum kegiatan pelatihan pada kader berakhir kami menundang perwakilan ibu baita dari masing-masing posyand untuk mendapatkan sosialisasi aplikasi Android. Setelah kegiatan berakhir para kader melakukan sosialisasi penggunaan SIPANDU berbasis android pada seluruh ibu balita di posyandu masing-masing.

\section{KESIMPULAN}

Pencatatan dan pelaporan sudah beralih dari manual menjadi online. Aplikasi SIPANDU sudah diterapkan oleh Posyandu Soka, Kamboja dan Kanthil pada hari buka Posyandu. Ibu balita sudah mendapatkan sosialisasi dari para kader terkait dengan penggunaan aplikasi SIPANDU berbasis android pada ponsel genggam. Ibu dapat memantau perkembangan bayi mereka masingmasing melalui HP yang dapat diakses kapanpun dan dimanapun. Pelayanan yang diberikan semakin cepat. Kader tidak lagi merasa khawatir apabila catatannya terselip atau hilang. Pelaporan ke pihak puskesmas semakin mudah karena pada saat kader menginputkan hasil pemeriksaan maka pada saat itu juga dapat langsung diakses pihak puskesmas maupun ibu balita. 


\section{DAFTAR PUSTAKA}

Dewi, D.,S.. 2017. Peran Komunikator Kader Posyandu Dalam Meningkatan Status Gizi Balita Di Posyandu Nurikelurahan Makroman Kecamatan Sambutan Kota Samarinda. eJournal Ilmu Komunikasi, ejournal.ilkom.fisip-unmul.ac.id Hal 272-282

Dikson, P. A.T, Suproojo, A dan Adiwidjaja, I. 2017. Peran Kader Posyandu terhadap Pembangunan Kesehatan Masyarakat. JISIP (Jurnal Ilmu Sosial dan Ilmu
Politik) ISSN. 2442-6962, Vol. 6 No 1 (2017) Hal 60-61

Iswarawanti, D.N. (2010). Kader Posyandu: Peranan dan Tantangan Pemberdayaan dalam Usaha Peningkatan Gizi Anak di Indonesia. Jurnal Manajemen Pelayanan Kesehatan volume 13 No. 04 Desember 2010 Hal 169-173.

Kementerian kesehatan RI Pusat Promosi Kesehatan. 2012. Ayok Ke Posyandu Setiap Bulan. www.promkes.depkes.go.id 